\title{
Benefits at 3 yrs of an asthma education programme coupled with regular reinforcement
}

\author{
J-M. Ignacio-García*, M. Pinto-Tenorio*, M.J. Chocrón-Giraldez*, F. Cabello-Rueda*, \\ A.I. López-Cozar Gil*, J-M. Ignacio-García\#, E. de Ramón-Garrido"
}

\begin{abstract}
Benefits at 3 yrs of an asthma education programme coupled with regular reinforcement. J-M. Ignacio-García, M. Pinto-Tenorio, M.J. Chocrón-Giraldez, F. Cabello-Rueda, A.I. López-Cozar Gil, J-M. Ignacio-García, E. de Ramón-Garrido. (C) ERS Journals Ltd 2002.

ABSTRACT: The benefits at $3 \mathrm{yrs}$ of an asthma self-management education programme coupled with educational reinforcement were assessed at follow-up visits in 63 adults with chronic asthma.

Changes in asthma-related morbidity parameters, lung function and use of different classes of drugs before intervention and after 1, 2 and 3 yrs of the asthma education programme were compared using Friedman one-way analysis of variance.

Improvements in the number of days off work or school, general practitioner consultations, admissions to emergency services, hospital admissions and nocturnal awakenings, as well as increases in forced expiratory volume in one second (FEV1), were significant. Comparison of data obtained at 1 yr and 2-3 yrs showed significant differences in the number of asthma-associated sleep disruptions, days off work or school and unscheduled visits to the general practitioner, as well as FEV1, but significant differences between the data obtained at 2 and 3 yrs were not observed. The percentage of patients using oral steroids had decreased significantly at $3 \mathrm{yrs}$.

In adults with chronic asthma, an asthma self-management education programme coupled with educational reinforcement was effective at decreasing asthma morbidity, improving lung function and decreasing consumption of oral steroids. Eur Respir J 2002; 20: 1095-1101.
\end{abstract}

\begin{abstract}
*Unit of Pneumonology, General Hospital of Serranía, Ronda, \#Dept of Clinical Pharmacology, Faculty of Health Sciences, Cádiz, and † Dept of Internal Medicine, Regional Hospital Carlos Haya, Málaga, Spain.
\end{abstract}

Correspondence: J-M. Ignacio-García C/Sevilla 103

E-29400 Ronda

Málaga

Spain

Fax: 34952876148

E-mail: jose1066@separ.es

Keywords: Asthma

education

peak expiratory flow rate

self-management

Received: February 232002

Accepted after revision: June 142002
Asthma continues to be an important cause of chronic morbidity. The disease has great economic impact because of the burden it places on health resources and the loss of productivity caused by absenteeism from work or school. During the 1990s, a variety of educational and self-management programmes were designed and implemented to train patients to control their asthma [1]. Logically, patients more knowledgeable about asthma and its treatment would be more likely to self-detect and react to acute exacerbations more efficiently. Patient education has been promoted as an important component of asthma management plans but it is still unclear which components of these self-management education programmes are essential to their success. Review of the literature published to date [2-27] indicates that education programmes that include general information on asthma, correct inhaler technique, acquisition of self-management skills based on clinical or functional data (home monitoring of peak expiratory flow rate (PEFR)) and an individualised written action plan lead to reduced morbidity and decreased use of healthcare services in adult patients with chronic asthma. Although it may be anticipated that improvements in asthma severity attributed to educational procedures and the development of self-management behaviour would have long-term effects, most studies have involved short-term programmes of up to 12 months.

The long-term effects of an asthma self-management education programme coupled with active educational reinforcement intervention at follow-up was assessed in a 3-yr prospective study.

\section{Methods}

The study was carried out in the outpatient asthma clinic of the 210-bed General Hospital of Serranía in Ronda, Spain. All patients aged 14-65 yrs whose asthma had been diagnosed $\geqslant 2$ yrs previously were invited to take part in a programme aimed at improving asthma self-management. Patients were consecutively recruited between January-June 1996. Those who agreed and gave written informed consent were studied for 3 yrs. All patients were assigned to the same asthma self-management education programme. The methods of obtaining outcome data consisted of review of the patient's medical records, registers of PEFR monitoring and diary cards, and structured interviews conducted during the study. A single physician was responsible for collection of data and modification of treatment at follow-up visits.

The initial assessment (visit 1) included complete 
medical history taking, physical examination, and spirometry to determine forced vital capacity (FVC), forced expiratory volume in one second (FEV1) and FEV1/FVC. Medical regimens were tailored to each patient's asthma pattern according to current guidelines and consensus reports on the diagnosis and treatment of asthma. Individual written therapeutic schedules were provided for each patient. Emphasis was placed on explaining correct inhaler technique and use of devices. Patients also received information on the general concepts of asthma and its management and provoking factors and how to avoid them, and were taught to measure their PEFR using a MiniWright Peak-Flow Meter (Clement Clarke International Ltd, Harlow, England). Measurements were made twice a day, just before inhaler use. Patients received diary cards to record diurnal and nocturnal symptoms, as well as the need for short-acting $\beta_{2}$-agonists (rescue medication).

One month after the first assessment (visit 2), the following key points were checked: inhaler technique, effective use of peak flow meters, compliance with patient's diary card, need for $\beta_{2}$-agonists, and information regarding the disease, as well as environmental triggers and how to avoid them. When required, further explanations were given and modifications to be implemented were discussed with the patient. Ongoing education was provided in the form of written information on the use and utility of various drugs (table 1) and recognition and appropriate management of acute exacerbations (tables 2-4). Patients with severe persistent asthma and those in whom, according to their PEFR diary card, the physician detected discrepancies between the patient's clinical condition and lung function, as well as patients poorly compliant in the educator's opinion, used peak flow readings as the basis for their therapeutic plan (table 3). In the remaining patients, after 1 month of daily PEFR measurement, the selfmanagement plan was based on clinical symptoms (table 4). Written action plans were delivered to each patient.

During the course of the follow-up visits, at $3,6,12$, 24 and 36 months, the programme and the patient's behaviour were reviewed, and drawbacks and decisions regarding treatment discussed. Educational reinforcement was provided at all visits, and, when treatment required modification, written self-action plans were delivered.

Morbidity outcomes included the number of days lost from work or school, unscheduled general practitioner visits, emergency department visits, to either the primary care centre or the acute care hospital, hospital admissions and asthma-related sleep disruptions (nocturnal awakenings). Morbidity data for the year prior to enrolment were compared with results obtained at 1,2 and 3 yrs after the programme was completed. Lung function, FEV1 expressed as an absolute value (in litres) and as a percentage of the predicted value, was measured at the beginning of the study and annually thereafter. The use of drugs, expressed as the percentage of patients using each class of drug, was measured at the beginning ( 0 months) and end of the study (36 months).
Table 1.-Information given to patients on drug use and utility

Sympathomimetic drugs of short half-life, $-\beta_{2}$-agonists (e.g. salbutamol, terbutaline)

Fast-acting bronchodilator drugs useful for the control of acute asthma symptoms

Not useful for long-term asthma control

An increase in the daily requirement for $\beta_{2}$-agonists means decompensation of the disease and, consequently, an increase in the need for anti-inflammatory agents to control the asthma

Sympathomimetic drugs of long half-life (e.g. formoterol, salmeterol)

Long-acting bronchodilator drugs

Should not be used for the control of acute asthma symptoms, which should be treated with salbutamol or terbutaline

Doses cannot be increased without the physician's permission

Theophylline

Bronchodilator drug

Doses cannot be increased without the physician's permission

Inhaled steroids (e.g. beclomethasone, budesonide, fluticasone)

Anti-inflammatory agent

Should always be used after bronchodilators

Very useful for achieving long-term stabilisation of the disease process; currently considered the most important medication for treating asthma

Does not relieve acute symptoms of asthma because rescue effect is lacking

It is necessary to take this medication regularly in order to have a normal life over the years

Oral steroids (e.g. prednisone, methylprednisone, deflazacort)

Anti-inflammatory agents which are sometimes necessary to stabilise exacerbations of acute asthma

Should be used appropriately following a physician's instructions

No need to be afraid of this modality of treatment if its use is adequate

Short-term courses are generally free from adverse events

Antibiotics

Acute episodes of asthma exacerbation are often confused with respiratory tract infections

Acute episodes of asthma exacerbation should be treated with anti-inflammatory agents and not with antibiotics

Antibiotics should be taken only in the case of bacterial decompensation with mucopurulent sputum (green)

\section{Statistical analysis}

The impact of educational reinforcement intervention on asthma morbidity parameters and lung function was assessed using Friedman one-way analysis of variance. Percentages of drug use before and after the intervention were analysed using Pearson's Chi-squared test; the association $(>1.96)$ or dissociation $(<-1.96)$ of consumption of different drugs at the beginning and end of the study was measured by means of typified residual calculation. Significance was set at $5 \%$.

\section{Results}

Of the 65 patients enrolled in the study, two (3\%) dropped out because of change of residence in a very 
Table 2. - Description of clinical symptoms according to the degree of decompensation

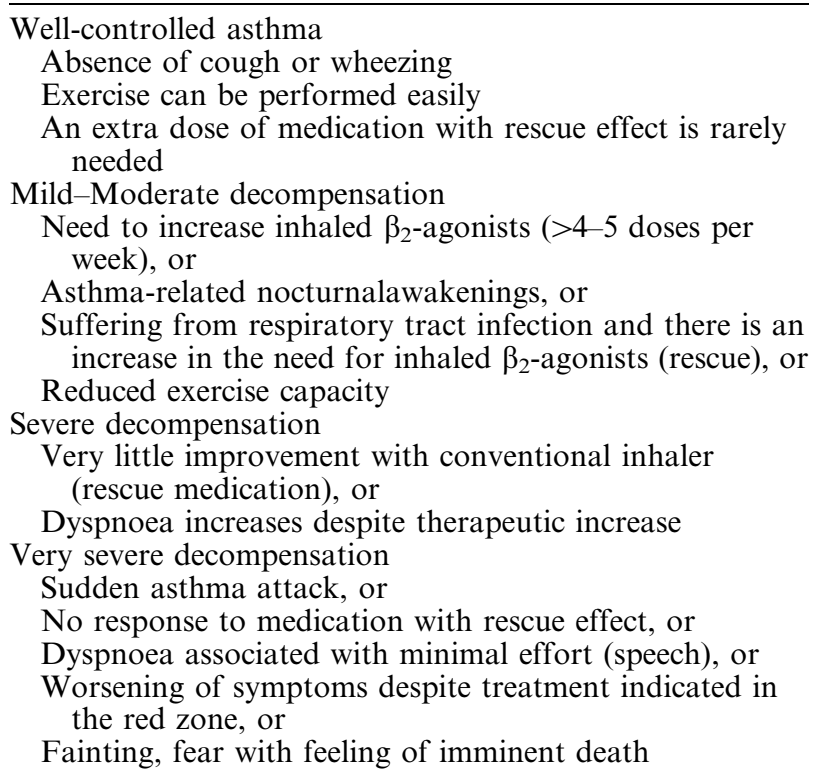

early phase of the study. The study population consisted of 63 patients, 19 males and 44 females, with age ranging 15-65 yrs (mean $40 \mathrm{yrs}$ ). Their sociodemographic and clinical data are shown in table 5. Fifty per cent of patients belonged to a low social class and only $16 \%$ were unemployed. Ten patients received a pension due to asthma. The majority of patients $(75 \%)$ suffered from moderate persistent asthma according to the classification of the Global Initiative for Asthma [28]. The selfmanagement plans used to guide therapy were based on symptoms in 39 patients and on PEFR measurements in 24

Asthma-related morbidity parameters, health service utilisation, and lung function before and during the 3-yr study period are shown in tables 6 and 7. The results of the Friedman test for the comparison of all variables at the four time points ( $1 \mathrm{yr}$ before the study and at 1,2 and 3 yrs) were significant $(\mathrm{p}<0.001)$. Comparison of data for 1,2 and 3 yrs of follow-up showed significant decreases in the number of days off work or school, unscheduled visits to the primary care physician and nocturnal awakenings, as well as

Table 3. - Self-management plan using peak flow to guide therapy

Controlled asthma, peak flow $>70 \%$

Patients will follow chronic asthma treatment indicated by his/her physician

Mild-Moderate asthma decompensation, peak flow between $50-70 \%$

Patients will be trained to adhere to the following theraputic plan:

Use of short-acting $\beta_{2}$-agonists for the control of symptoms when needed

Double dose of inhaled steroid for twice the number of days needed to return to baseline condition (e.g. if 3 days are needed to return to the baseline condition, double dose of inhaled steroid should be maintained for 6 days)

Once the cycle is finished and the patient's condition stable, return to programmed chronic treatment

Severe asthma decompensation, peak flow between $30-50 \%$

Patients in this therapeutic group should adhere to the following treatment:

Use of short-acting $\beta_{2}$-agonists for the control of symptoms when needed

Start a short-term course of oral steroids (prednisone $30-40 \mathrm{mg} \cdot \mathrm{day}^{-1}$ or other steroids at equivalent doses). This therapeutic plan should be maintained for twice the number of days needed to return to baseline condition

When oral steroid treatment is needed, patients should contact medical staff in 24 to $72 \mathrm{~h}$ for confirmation

Very severe asthma decompensation, peak flow $<30 \%$

Patients at this stage are at risk of sudden death, for this reason urgent treatment must be immediately instituted:

Short-acting $\beta_{2}$-agonists for the control of symptoms as many times as needed, contact medical staff immediately or go directly to hospital

Table 4. - Self-management plan using symptoms to guide therapy

\section{Controlled asthma}

Patients will follow chronic asthma treatment indicated by their physician

Mild-Moderate asthma decompensation

Patients will be trained to adhere to the following theraputic plan:

Use of short-acting $\beta_{2}$-agonists for the control of symptoms, when needed

Double dose of inhaled steroid for twice the number of days needed to return to baseline condition (e.g. if 3 days are needed to return to the baseline condition, double dose of inhaled steroid should be maintained for 6 days)

Once the cycle is finished and the patient's condition stable, return to programmed chronic treatment

Severe asthma decompensation

Patients in this therapeutic group should adhere to the following treatment:

Use short-acting $\beta_{2}$-agonists for the control of symptoms when needed

Start a short-term course of oral steroids (prednisone $30-40 \mathrm{mg} \cdot \mathrm{day}^{-1}$ or other steroids at equivalent doses). This therapeutic plan should be maintained for a period of 10-14 days

When oral steroid treatment is needed, patients should contact his/her physician in 24 to $72 \mathrm{~h}$ for confirmation.

Very severe asthma decompensation

Patients at this stage are at risk of sudden death, for this reason urgent treatment must be immediately instituted:

Short-acting $\beta_{2}$-agonists for the control of symptoms as many times as needed and go directly to hospital 
Table 5. - Sociodemographic and clinical data

\begin{tabular}{|c|c|}
\hline Patients $\mathrm{n}$ & 63 \\
\hline Age yrs ${ }^{\#}$ & $39.5 \pm 1.93$ \\
\hline Sex male/female $n$ & $1 \overline{9 / 4} 4$ \\
\hline \multicolumn{2}{|l|}{ Social status $n$} \\
\hline Very low & 3 \\
\hline Low & 33 \\
\hline Medium & 23 \\
\hline High & 4 \\
\hline \multicolumn{2}{|l|}{ Smoking habit $\mathrm{n}$} \\
\hline Smoker & 14 \\
\hline Nonsmoker & 38 \\
\hline Exsmoker & 11 \\
\hline \multicolumn{2}{|l|}{ Asthma severity $\mathrm{n}$} \\
\hline Mild & 3 \\
\hline Moderate & 47 \\
\hline Severe & 13 \\
\hline
\end{tabular}

${ }^{\#}:$ mean $\pm \mathrm{SD} ;{ }^{\bullet}$ : Global Initiative for Asthma classification [28].

significant improvements in FEV1 $(\mathrm{p}<0.001)$. However, significant differences between the data obtained at 2 and 3 yrs were not observerd. All patients (100\%) had inhaled steroids prescribed before and at the end of the study. Conversely, there were no significant differences in the percentage of patients using longacting $\beta_{2}$-agonists or theophylline at baseline and at the end of the study (57 versus $65 \%$ and 14 versus $6.3 \%$, respectively). However, the percentage of patients using oral steroids had decreased significantly at the end of the study (22 versus $11 \%, \mathrm{p}<0.05)$.

\section{Discussion}

A number of previous studies, including a controlled trial conducted by the present authors' group [15], have demonstrated that training in asthma selfmanagement that involves self-monitoring by either PEFR or symptoms appears to improve health outcomes for adults with asthma, at least in the short term [2-14, 16-27]. Training programmes which enable people to adjust their medication using a written action plan appear to be more effective than other forms of asthma self-management [25]. However, the benefits of education programmes based on self-management plans in the long-term follow-up of asthmatic patients have yet to be determined.

To the present authors' knowledge, there are only two previous studies on the long-term follow-up of

Table 6. - Healthcare utilisation, morbidity and lung function before and during the study

\begin{tabular}{|c|c|c|c|c|}
\hline & \multirow[t]{2}{*}{ Before study } & \multicolumn{3}{|c|}{ During study } \\
\hline & & $1 \mathrm{yr}$ & $2 \mathrm{yrs}$ & $3 \mathrm{yrs}$ \\
\hline $\begin{array}{l}\text { Time lost from } \\
\text { work/school days }\end{array}$ & $38.12 \pm 61.83(0-360)$ & $15.13 \pm 33.79(0-180)$ & $5.85 \pm 17.92(0-120)$ & $4.25 \pm 9.20(0-30)$ \\
\hline $\begin{array}{l}\text { Primary care visits } n \\
\text { Emergency visits } n\end{array}$ & $6.78 \pm 5.96(0-42)$ & $2.44 \pm 2.59(0-12)$ & $1.49 \pm 1.81(0-8)$ & $1.29 \pm 1.79(0-10)$ \\
\hline Primary care & $1.67 \pm 1.78(0-8)$ & $0.43 \pm 1.04(0-6)$ & $0.24 \pm 0.73(0-4)$ & $0.25 \pm 0.93(0-6)$ \\
\hline Acute care hospital & $0.79 \pm 0.12(0-6)$ & $0.21 \pm 0.60(0-3)$ & $0.21 \pm 0.63(0-3)$ & $0.13 \pm 0.38(0-2)$ \\
\hline Hospitalisations n & $0.10 \pm 0.30(0-1)$ & $0.016 \pm 0.13(0-1)$ & $0.016 \pm 0.13(0-1)$ & $0.016 \pm 0.13(0-1)$ \\
\hline $\begin{array}{l}\text { Nocturnal awakenings } \\
\mathrm{n}\end{array}$ & $120.43 \pm 122.5(0-360)$ & $36.61 \pm \overline{65} .56(0-300)$ & $20.48 \pm 53.52(0-300)$ & $16.43 \pm \overline{47.99}(0-300)$ \\
\hline $\begin{array}{l}\text { FEV1 } \% \text { pred } \\
\text { L }\end{array}$ & $\begin{array}{l}72.71 \pm 19.50(25-108) \\
2.14 \pm 0.68(0.85-3.89)\end{array}$ & $\begin{array}{l}78.55 \pm 17.62(36-112) \\
2.30 \pm 0.72(0.98-3.97)\end{array}$ & $\begin{array}{l}81.29 \pm 18.89(34-118) \\
2.39 \pm 0.75(0.98-4.13)\end{array}$ & $\begin{array}{l}83.23 \pm 18.76(31-121) \\
2.42 \pm 0.72(0.85-4.13)\end{array}$ \\
\hline
\end{tabular}

Data are presented as mean $\pm \mathrm{SD}$ (range). FEV1: forced expiratory volume in one second; \% pred: percentage of the predicted value.

Table 7.-Morbidity and lung function parameters before and during the study

\begin{tabular}{|c|c|c|c|c|}
\hline & \multirow[t]{2}{*}{ Before study } & \multicolumn{3}{|c|}{ During study } \\
\hline & & $1 \mathrm{yr}$ & 2 yrs & 3 yrs \\
\hline Time lost from work/school days & $5(4-7)$ & $3.5(0-12)$ & $0(0-4.75)$ & $0(0-3.75)^{* * *, \#}$ \\
\hline Primary care visits $\mathrm{n}$ & $5(4-7)$ & $2(1-3)$ & $1(0-2)$ & 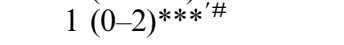 \\
\hline \multicolumn{5}{|l|}{ Emergency visits $n$} \\
\hline Primary care & $1(0-3)$ & $0(0-0)$ & $0(0-0)$ & $0(0-0)$ \\
\hline Acute care hospital & $1(0-1)$ & $0(0-0)$ & $0(0-0)$ & $0(0-0)$ \\
\hline Hospitalisations $\mathrm{n}$ & $0(0-0)$ & $0(0-0)$ & $0(0-0)$ & $0(0-0)$ \\
\hline Nocturnal awakenings $\mathrm{n}$ & $60(24-225)$ & $10(0-33)$ & $4(0-11)$ & $0(3-10)^{* * *, \#}$ \\
\hline FEV $1 \%$ pred & $76.50(64.75-85.50)$ & $81.50(67.75-90)$ & $85(70-94.50)$ & $85.50(71.50-97)^{* * *, \#}$ \\
\hline $\mathrm{L}$ & $2.200(1.715-2.562)$ & $2.220(1.805-2.715)$ & $2.450(1.850-2.850)$ & $2.360(1.885-2.282)^{* * *, \#}$ \\
\hline
\end{tabular}

Data are presented as median (interquartile range). FEV1: forced expiratory volume in one second; \% pred: percentage of the predicted value. Comparison of all variables at the four time points were significant $(\mathrm{p}<0.001)$. ***: $\mathrm{p}<0.001$ for comparison at 1,2 and 3 yrs; ${ }^{\#}$ : $\mathrm{p}=$ NS for comparison at 2 and 3 yrs (Friedman one-way analysis of variance). 
patients who have completed an asthma selfmanagement programme, both conducted in a rural indigenous Maori community [29, 30]. Of the 69 paticipants who originally enrolled in the 6-month "credit card" asthma self-management plan, 58 were surveyed 2 yrs after completion of the programme and 47 after 6 yrs. Participants were surveyed using a questionnaire and there was no further educational or therapeutic involvement with the participants or general practitioners by the research group. Although patients were still experiencing reduced morbidity from their asthma 6 yrs after the end of the selfmanagement programme, the benefits were less than those observed at 2 yrs. Since these results were achieved without any ongoing intervention, the authors of the studies concluded that, to obtain enduring benefits from asthma education programmes, reinforcement of self-mangement skills seems to be an essential component of any follow-up [29, 30].

The present study was designed to assess the impact of a self-management education programme, previously found to be effective in a controlled trial [15], coupled with educational reinforcement on the outcome of adult asthma patients at 3 yrs. The participation rate, with $97 \%$ of the 65 patients taking part during the 3-yr follow-up period, gives consistency to the results obtained. Only two patients discontinued the study, and for reasons unrelated to the programme. When data recorded for the four time periods (previous 12 months and at 1,2 and 3 yrs) were compared, a significant decrease in asthmarelated morbidity and improvement in lung function was found. This finding indirectly indicates that improvement in the patient's condition is highly significant at $1 \mathrm{yr}$. After this period, although further reduction in the number of emergency visits and hospitalisations did not occur, lung function and other morbidity parameters, such as number of days lost from work or school, unscheduled visits to the primary care physician and asthma-related sleep disruptions, showed significant improvement at 2 yrs. It is interesting to note that the benefits of the self-management education plan appeared to be sustained and remained unchanged at 3 yrs. Moreover, the fact that all patients had inhaled steroids prescribed and that a reduction in the use of this medication, as well as of inhaled $\beta_{2}$-agonist and oral theophylline, was not observed suggests that the improvement in morbidity noted in this study was related to improved compliance rather than increased prescribed doses of these agents. Moreover, that beneficial results were obtained in the present study despite quite different thresholds for intervention being used compared to other studies further reflects the fact that it is the concept rather than the detail that works, and this reinforces the hypothesis that giving control to the patient enhances compliance. Better control of asthma symptoms related to the effectiveness of the asthma self-management education plan is reflected also by a significant decrease in the number of courses of oral steroids needed during the study period. The benefits obtained from the selfmanagement education programme were similar for patients using peak flow monitoring or clinical symptoms alone, which further emphasises the importance of active individualised educational reinforcement at follow-up.

However, some potential disadvantages of the "before and after" nature of the study design and the potential areas of bias, including the lack of a control group, selection bias, use of retrospective data, Hawthorne effect and the influence of greater dedication on the part of the physician resulting in better treatment and follow-up, merit discussion. The present study was carried out in a group of consecutive patients attending the outpatient asthma clinic with a stable clinical condition during the 4 weeks prior to inclusion in the study but who, nevertheless, had used different healthcare services during the last year on at least one occasion due to an asthma exacerbation episode (the majority of the patients suffered from moderate persistent asthma). From a clinical and sociodemographic point of view, the study population was representative of the healthcare demand of the asthma population visited in routine daily practice. Data on asthma-related hospital admissions and emergency department visits are recorded in a systematic and centralised manner in all medical records, and other asthma morbidity parameters are included in the data collection form for asthma patients. In respect of "recall" of sleep disturbance (nocturnal awakening), at the time of the study design, asthma patients with positive morbidity data had outpatient visits scheduled at 3-month intervals and the presence of any mobidity indicator was recorded in the patients' medical records. Accordingly, "recall" of sleep disturbance may be expected to be reasonably accurate.

The initial benefits of the programme remaining unchanged at 3 yrs may be explained by closer control of patients, better adherence to medication associated with the person's knowledge of being under study or a more rational therapeutic approach due to better control of asthma symptoms. With regard to the lack of a control group, it may be argued that, in a previous controlled trial with a similar design but of shorter duration [15], it was found that closer control of patients in the absence of asthma education was not associated with benefits in terms of use of healthcare services, lung function or medication use. Data from others have shown that the benefits of asthma education programmes without reinforcement strategies decrease over time [30]. In the present study, educational reinforcement was delivered annually, and, under normal conditions, clinical practice guidelines recommend follow-up visits scheduled at 3-6-month intervals. Conversely, benefit is unlikely to be due to greater use of medication related to closer control or follow-up of patients given that, at study entry, patients had had their asthma stabilised and data on drug use at the end of the study showed a significant decrease in the use of oral steroids and no significant changes in the use of the remaining classes of drugs. For these reasons, benefits associated with the asthma education programme coupled with regular reinforcement can reasonably be considered the consequence of behaviour changes and an increase 
in adherence to medication regimens induced by all measures included in the education programme that, on the one hand, allow the patient to act without delay in the case of exacerbation their asthma, and, on the other, contribute to making the patient less vulnerable to different factors that favour the development of asthma exacerbation episodes over the time-course of the disease.

In conclusion, an asthma self-management programme coupled with an annual educational intervention was effective in decreasing morbidity, improving lung function and decreasing consumption of oral steroids during a follow-up period of 3 yrs. However, larger-scale studies are needed to confirm the effects of patient education on long-term asthma morbidity. The self-management advice contained in management plans for adult asthma should be updated and potential deficiencies corrected in accordance with the results of recent major trials and evidence-based recommendations [31-33]. In this respect, definition of the daily effective dose of inhaled steroids for long-term treatment [34, 35], use of longacting $\beta_{2}$-agonists rather than doubling the dose of inhaled steroids [36, 37] and the development of combination inhalers [38] and add-on therapeutic strategies [39, 40] warrant further investigation.

Acknowledgements. The authors would like to thank M. Pulido for editing the manuscript and editorial assistance.

\section{References}

1. National Heart, Lung, and Blood Institute. Guidelines for the Diagnosis and Management of Asthma. Publication No. 97-4051. Bethesda, MD, USA, National Institutes of Health, 1997.

2. Allen RM, Jones MP, Oldenburg B. Randomised trial of an asthma self-management programme for adults. Thorax 1995; 50: 731-738.

3. Ayres JG, Campbell LM. A controlled assessment of an asthma self-management plan involving a budesonide dose regimen. Eur Respir J 1996; 9: 886-892.

4. Bailey WC, Richards JM, Brooks CM, Soong SJ, Windsor RA, Manzella BA. A randomised trial to improve self-management practice of adults with asthma. Arch Intern Med 1990; 150: 1664-1668.

5. Berg J, Dunbar-Jacob J, Sereika SM. An evaluation of a self-management program for adults with asthma. Clin Nursing Res 1997; 6: 225-238.

6. Brewin AM, Hughes JA. Effect of patient education on asthma management. Br J Nursing 1995; 4: 81-101.

7. Charlton I, Charlton G, Broomfield J, Mullee MA. Evaluation of peak flow and symptoms only selfmanagement plans for control of asthma in general practice. BMJ 1990; 301: 1355-1359.

8. Côté J, Cartier A, Robichaud P, et al. Influence on asthma morbidity of asthma education programs based on self-management plans following treatment optimization. Am J Respir Crit Care Med 1997; 155: 1509-1514.

9. Cowie RL, Revitt SG, Underwood MF, Field SK. The effect of a peak flow-based action plan in the prevention of exacerbations of asthma. Chest 1997; 112: $1534-1538$

10. Garrett J, Fenwick JM, Taylor G, Mitchell E, Stewart J, Rea H. Prospective controlled evaluation of the effect of a community based asthma education centre in a multiracial working class neighbourhood. Thorax 1994; 49: 976-983.

11. Grampian Asthma Study of Integrated Care (GRASSIC). Effectiveness of routine self monitoring of peak flow in patients with asthma. BMJ 1994; 308: 564-567.

12. Hilton S, Sibbald B, Anderson HR, Freeling P. Controlled evaluation of the effects of patient education on asthma morbidity in general practice. Lancet 1986; i: 26-27.

13. D'Souza W, Crane J, Burgess A, et al. Communitybased asthma care: trial of a "credit card" asthma selfmanagement plan. Eur Respir J 1994; 7: 1260-1265.

14. D'Souza W, Burgess C, Ayson M, Crane J, Pearce N, Beasley R. Trial of a "credit card" asthma selfmanagement plan in a "high risk" group of patients with asthma. J Allergy Clin Immunol 1996; 97: 10851092.

15. Ignacio-García JM, Gonzalez-Santos P. Asthma selfmanagement education program by home monitoring of peak expiratory flow. Am J Respir Crit Care Med 1995; 151: 353-359.

16. Jones KP, Mullee MA, Middleton M, Chapman E, Holgate ST, and the British Thoracic Society Research Committee. Peak flow based asthma self-management: a randomised controlled study in general practice. Thorax 1995; 50: 851-857.

17. Kotses H, Bernstein IL, Bernstein DI, et al. A selfmanagement program for adult asthma. Part I: development and evaluation. J Allergy Clin Immunol 1995; 95: 529-540.

18. Kotses H, Stout C, McConnaughty K, Winder JA, Creer TL. Evaluation of individualized asthma selfmanagement programs. J Asthma 1996; 33: 113-118.

19. Lahdensuo A, Haahtela T, Herrala J, et al. Randomised comparison of guided self management and traditional treatment of asthma over one year. $B M J$ 1996; 312: 748-752.

20. Mayo PH, Richman J, Harris HW. Results of a program to reduce admissions for adult asthma. Ann Intern Med 1990; 112: 864-871.

21. Neri M, Migliori GB, Spanevello A, et al. Economic analysis of two structured treatment and teaching programs on asthma. Allergy 1996; 51: 313-319.

22. Turner MO, Taylor D, Bennett R, Fitzgerald JM. A randomized trial comparing peak expiratory flow and symptom self-management plans for patients with asthma attending a primary care clinic. Am J Respir Crit Care Med 1998; 157: 540-546.

23. Wilson SR, Scamagas $\mathrm{P}$, German DF, et al. A controlled trial of two forms of self-management education for adults with asthma. Am J Med 1993; 94 : 564-576.

24. Yoon R, McKenzie DK, Bauman A, Miles DA. Controlled trial evaluation of an asthma education programme for adults. Thorax 1993; 48: 1110-1116.

25. Zeiger RS, Heller S, Mellon MH, Wald J, Falkoff R, Schatz M. Facilitated referral to asthma specialist reduces relapses in asthma emergency room visits. J Allergy Clin Immunol 1991; 87: 1160-1168.

26. Gibson PG, Coughlan J, Wilson AJ, Self-management education and regular practitioner review for adults 
with asthma (Cochrane Review). In: The Cochrane Database of Systematic Reviews. The Cochrane Library 2002, Issue 3. Oxford, Update software, 2002.

27. Beasley R, Crane J. Reducing asthma mortality with the asthma self-management plan system of care. Am J Respir Crit Care Med 2001; 163: 3-4.

28. Global Initiative for Asthma. Global Strategy for Asthma Management and Prevention NHLBI/ WHO Workshop Report. Publication No. 95-3659. Bethesda, MD, USA, National Institutes of Health, National Heart, Lung, and Blood Institute, 1995.

29. D'Souza WJ, Te Karu H, Fox C, et al. Long-term reduction in asthma morbidity following an asthma self-management programme. Eur Respir J 1998; 11: 611-616.

30. D'Souza WJ, Slater T, Fox C, et al. Asthma morbidity 6 yrs after an effective asthma self-management programme in a Maori community. Eur Respir $J$ 2000; 15: 464-469.

31. FitzGerald JM. Development and implementation of asthma guidelines. Can Respir J 1998; 5 (Suppl. A): $85 \mathrm{~A}-88 \mathrm{~A}$.

32. Boulet LP, Bai TR, Becker A, et al. What is new since the last (1999) Canadian Asthma Consensus Guidelines? Can Respir J 2001; 8: 65-68.

33. FitzGerald M. Acute asthma. BMJ 2001; 323: 841845.

34. Foresi A, Morelli MC, Catena E, on behalf of the
Italian Study Group. Low-dose budesonide with the addition of an increased dose during exacerbations is effective in long-term asthma control. Chest 2000; 117: 440-446.

35. Reddel HK, Jenkins CR, Marks GB, et al. Optimal asthma control, starting with high doses of inhaled budesonide. Eur Respir J 2000; 16: 226-235.

36. Kelsen SC, Church NL, Gillman SA, et al. Salmeterol added to inhaled corticosteroid therapy is superior to doubling the dose of inhaled corticosteroids: a randomized clinical trial. J Asthma 1999; 36: 703-715.

37. O'Byrne PM, Barnes PJ, Rodriguez-Roisin R, et al. Low dose inhaled budesonide and formoterol in mild persistent asthma: the OPTIMA randomized trial. Am J Respir Crit Care Med 2001; 164: 1336-1338.

38. Lalloo U. Symbicort: controlling asthma in adults. Respir Med 2002; 96 (Suppl. A): S16-S22.

39. Ducharme F, Hicks G, Kakuma R. Addition of antileukotriene agents to inhaled corticosteroids for chronic asthma (Cochrane Review). In: The Cochrane Library, 2002, Issue 2. Oxford, Update Software, 2002.

40. Holgate S, Bousquet J, Wenzel S, Fox H, Liu J, Castellsague J. Efficacy of omalizumab, an antiimmunoglobulin $\mathrm{E}$ antibody, in patients with allergic asthma at high risk of serious asthma-related morbidity and mortality. Curr Med Res Opin 2001; 17: $233-$ 240. 